\title{
A Fundamental Model of Wax Deposition in Subsea Oil Pipelines
}

\author{
Zhenyu Huang \\ Dept. of Chemical Engineering, University of Michigan, Ann Arbor, MI 48109 \\ Hyun Su Lee \\ Dept. of Chemical Engineering, University of Michigan, Ann Arbor, MI 48109 \\ Production Assurance Technology, ConocoPhillips, Bartlesville, OK 74004 \\ Michael Senra and H. Scott Fogler \\ Dept. of Chemical Engineering, University of Michigan, Ann Arbor, MI 48109
}

DOI 10.1002/aic.12517

Published online February 15, 2011 in Wiley Online Library (wileyonlinelibrary.com).

\begin{abstract}
Wax deposition in subsea pipelines is a significant economic issue in the petroleum industry. A mathematical model has been developed to predict the increase in both the deposit thickness and the wax fraction of the deposit using a fundamental analysis of the heat and mass transfer for laminar and turbulent flow conditions. It was found that the precipitation of wax in the oil is a competing phenomenon with deposition. Two existing approaches consider either no precipitation (the independent heat and mass transfer model) or instantaneous precipitation (the solubility model) and result in either an overprediction or an underprediction of deposit thickness. By accounting for the kinetics of wax precipitation of wax in the oil (the kinetic model), accurate predictions for wax deposition for both lab-scale and pilot-scale flow-loop experiments with three different oils were achieved. Furthermore, this kinetic model for wax precipitation in the oil was used to compare field-scale deposition predictions for different oils. (C) 2011 American Institute of Chemical Engineers AIChE J, 57: 2955-2964, 2011
\end{abstract}

Keywords: petroleum, diffusion (mass transfer, heat transfer), wax deposition, modeling

\section{Introduction}

Crude oil is a mixture of waxes, aromatics, naphthenes, asphaltenes, and resins. At typical reservoir temperatures $\left(70-150^{\circ} \mathrm{C}\right)$ and pressures (>2000 psi), wax molecules are dissolved in the crude oil. As the crude oil flows through a subsea pipeline resting on the ocean floor at $4^{\circ} \mathrm{C}$, the temperature of oil decreases below its cloud-point temperature (or wax appearance temperature, WAT) because of the heat loss to the surroundings. The waxes in the oil form deposits on

\footnotetext{
Correspondence concerning this article should be addressed to H. Scott Fogler at sfogler@umich.edu.

(C) 2011 American Institute of Chemical Engineers
}

the cold pipe wall, which has become a major problem for flow assurance. In the worst case, production must be stopped and the plugged portion of the pipeline must be replaced. The cost of this replacement and downtime is estimated to be $\sim \$ 30,000,000$ per incident. In one case, the wax deposition was so severe and frequent that an off-shore platform in the North Sea had to be abandoned at a cost of about $\$ 100,000,000 .^{1}$ Remediation techniques for deposition have become a vital part in flow assurance research. One of the most conventional mechanical remediation methods used is pigging where an inspection gauge or a "pig" is sent in the pipeline to scrape off the wax. ${ }^{2}$ However, if the wax deposit builds up rather rapidly and hardens, the "pig" can become stuck in the pipe as was the case in a pipeline in the 


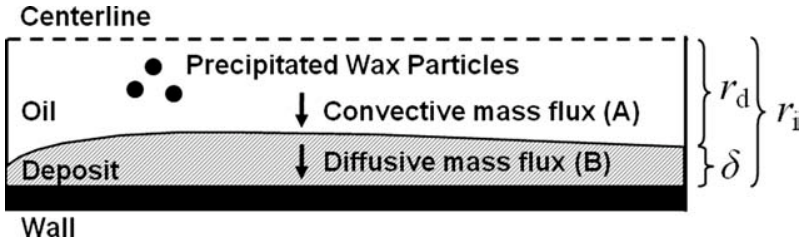

Figure 1. Schematic of the MWP model for wax deposition in subsea pipelines. ${ }^{9}$

Gulf of Mexico. ${ }^{3}$ Another technique takes the advantage of fused chemical reactions that uses an exothermic reaction with controlled heat emission. ${ }^{4,5}$

Deposition modeling has become an important method to ensure efficiency in utilizing these above remediative techniques. A number of deposition mechanisms have been suggested including molecular diffusion, shear dispersion, particle agglomeration, Brownian diffusion, and gravity settling. ${ }^{6-8}$ Among these mechanisms, molecular diffusion has been shown to be the dominant process in wax deposition. ${ }^{9}$ According to this mechanism, a concentration gradient first occurs when the wax molecules near the cold wall precipitate out of the solution to form an incipient layer of deposit. This precipitation reduces the concentration of wax near the wall and results in a wax concentration gradient between the bulk and the wall. The concentration gradient is the driving force for wax deposition, which leads to the transport of wax molecules toward the wall. As shown in Figure 1, this radial transport of wax molecules consists of two mass fluxes: the convective mass flux of wax molecules from the bulk toward the deposit interface (A) and the internal diffusive flux of paraffin molecules in the deposit layer (B). In addition, the convective mass flux of the wax molecules from the bulk to the wall is affected by their precipitation when they reach a region of the fluid where the oil is below the cloud-point temperature. We shall consider three scenarios for this step: (1) no precipitation of wax molecules in the oil until they reach the interface; (2) instantaneous precipitation of wax molecules; and (3) slow precipitation of wax molecules. These three scenarios form the basis of our deposition model called the Michigan Wax Predictor (MWP).

The resulting wax deposit consists of a network structure formed by the precipitated wax molecules, while a small amount of oil is entrapped in this structure. The most important output parameter in wax deposition modeling is the growth of deposit thickness. Additionally, the wax fraction in the deposit is another crucial output for deposition modeling because it influences the strength of the deposit, which is important parameter for its removal by pigging. Early models have used molecular diffusion as the basis to predict wax deposition in oil pipelines. ${ }^{6,8}$ Unfortunately, these models assumed that the wax content inside the deposit to be constant. More recent research shows that the wax fraction in the deposit increases as the deposit thickens. ${ }^{10}$ This increase in the wax fraction in the deposit is called aging and it results in an increase in the thermal conductivity of the deposit and a decrease in the molecular diffusivity of wax in the deposit. To overcome the limitations in previous models, Singh et al. developed a comprehensive mass balance for the wax deposit to predict both the growth of the deposit thick- ness and the increase of wax fraction with time under laminar flow conditions. ${ }^{10}$ Excellent agreement with the experimental data was found in the laminar flow regime where the heat and mass transfer correlations used in this model are independent of each other. This decoupling of the heat and mass transfer neglects the precipitation of wax molecules in the oil phase and corresponds to Scenario (1) for molecular diffusion. However, in turbulent flow conditions, the heat and mass transfer are not independent because there can be significant precipitation of wax molecules in the oil phase. ${ }^{11}$ The precipitated wax particles do not deposit on the pipe wall but rather flow with the oil. More importantly, the precipitation of wax reduces the amount of dissolved wax molecules in the oil that can be potentially transported to the wall and deposit. Therefore, this approach of using independent heat and mass transfer (IHMT) correlations (also known as the "Chilton-Colburn analogy" in turbulent flow) represents the upper bound of the deposit thickness. A refinement of this model used the "solubility method" for the oil phase that assumes precipitation occurs instantaneously once the oil temperature falls below the WAT and that the concentration of wax depends solely on the solubility of wax in the oil. ${ }^{12}$ This approach represents Scenario (2) for the molecular diffusion discussed previously. However, by overpredicting the precipitation rate, this "solubility method" underestimates the remaining dissolved wax molecules in the boundary layer of the oil. These dissolved wax molecules can eventually reach the wall and deposit. Therefore, this approach provides the lower bound of the deposit thickness. Although these upper bound and lower bound provide physical limits of deposition modeling, a deposition model that falls between these two bounds and accounts for the kinetics of the precipitation of wax in the oil phase (Scenario (3)) is still needed to better describe the deposition phenomena in turbulent flow conditions.

In this research, the precipitation kinetics of wax molecules in the oil under turbulent flow conditions have been investigated using the finite difference method to solve the equations for heat and mass transfer. This model is referred to as the MWP in this study. It is shown that the MWP can accurately predict both the growth of the deposit thickness and the increase in the wax fraction of the deposit for the deposition experiments for both lab-scale laminar flow and pilot-scale turbulent flow. Finally, the MWP is used to study wax deposition in field-scale pipeline systems.

\section{Model Development}

The MWP first evaluates the transport characteristics in a pipe flow system and then applies molecular diffusion as the deposition mechanism for wax deposition prediction, which will be discussed in subsequent sections. The major inputs of the model are shown in Table 1. The major outputs of the model include the thickness and the wax fraction of the deposit.

\section{Heat and mass transfer}

Before we elaborate the kinetic method in this study, the two conventional approaches, the IHMT method ${ }^{10}$ and the solubility method, ${ }^{11}$ will first be discussed. 
Table 1. Major Inputs of the MWP

$\begin{array}{ll}\text { Operating conditions } & \text { Inlet temperature of the oil/coolant } \\ & \text { Flow rate of the oil/coolant } \\ \text { Oil properties } & \text { Density of the oil/coolant } \\ & \text { Solubility of the oil } \\ \text { Viscosity of the oil/coolant } & \text { Thermal conductivity of the oil/wax/coolant } \\ & \text { Specific heat of the oil/coolant }\end{array}$

\section{Independent heat and mass transfer method as the upper bound}

This approach is first used by Singh and Fogler for wax deposition modeling in laminar flow where the transport correlation by Seider and Tate was used ${ }^{13}$

$$
\left\{\begin{array}{l}
\mathrm{Nu}=1.24\left(\frac{d}{L} \operatorname{Re} \operatorname{Pr}\right)^{(1 / 3)} \\
\mathrm{Sh}=1.24\left(\frac{d}{L} \operatorname{Re~Sc}\right)^{(1 / 3)}
\end{array}\right.
$$

The correlation for mass transfer above assumes that bulk precipitation does not occur during mass transfer, which resembles to Scenario (1) as discussed in the previous section. However, work has shown that for turbulent flow conditions this assumption is invalid as there is significant precipitation of wax molecules in the bulk oil. ${ }^{11}$ As a result, the amount of the wax molecules dissolved in the oil is overestimated in the IHMT model. As it is the dissolved molecules that can be transported toward the wall and deposit, this approach leads to an overestimation of the growth of the deposit and represents the upper bound of the deposit thickness profile.

\section{Solubility method as the lower bound}

To account for the precipitation of wax molecules in the oil phase, Venkatesan proposed a lower bound called the "solubility method." This method calculates the convective mass transfer rate assuming a dependency between heat and mass transfer. ${ }^{12}$ In their study, the Dittus-Boelter heat transfer correlation is used for turbulent flow, ${ }^{14}$ while the mass transfer is dependent on heat transfer based on the solubility of wax, $C_{\mathrm{ws}}(T)$

$$
\left\{\begin{array}{l}
\mathrm{Nu}=0.023 \operatorname{Re}^{0.83} \operatorname{Pr}^{0.33} \\
\mathrm{Sh}=\left.N u\left(\frac{d C_{\mathrm{ws}}(T)}{d T}\right)\right|_{\text {interface }} \frac{T_{\text {bulk }}-T_{\text {interface }}}{C_{\text {ws, bulk }}(T)-C_{\text {ws,interface }}(T)}
\end{array}\right.
$$

By combining the Nusselt number with the solubility of wax as shown in Eq. 2, this approach calculates the mass transfer rate (i.e., the Sherwood number) assuming that the concentration of wax in the oil follows thermodynamic equilibrium with the precipitated solid wax particles. This assumption indicates that during radial transportation, all the supersaturated wax molecules will precipitate instantaneously in the oil and form particles when they reach a region where the temperature falls below the WAT. These precipitated wax particles will flow with the oil and no longer contribute to deposition, which corresponds to Scenario (2) as discussed in the previous section. More importantly, as the supersaturated wax molecules are assumed to precipitate instantane- ously in the oil, very few of them can remain in the liquid, diffuse to the deposit interface and then become part of the deposit. Therefore, the solubility model tends to underestimate the growth rate of the wax deposit. The concentration profiles of wax in the oil obtained by these two methods are shown in Figure 2. It can be seen that in reality, the concentration profile in the oil phase is theoretically bounded by the IHMT model as the upper end and the solubility model as the lower end, depending on the kinetics of precipitation.

\section{Kinetic model}

To quantify the effect of precipitation kinetics on wax deposition in this study, a deposition model (the MWP) is developed using numerical methods instead of using established empirical correlations to solve transport equations. The MWP first evaluates the heat and mass transfer by solving the following equations. (Heat transfer)

$$
V_{\mathrm{z}} \frac{\partial T}{\partial z}=\frac{1}{r} \frac{\partial}{\partial r}\left[r\left(\varepsilon_{\mathrm{H}}+\alpha_{\mathrm{T}}\right) \frac{\partial T}{\partial r}\right]
$$

(Mass transfer)

$$
V_{\mathrm{z}} \frac{\partial C}{\partial z}=\frac{1}{r} \frac{\partial}{\partial r}\left[r\left(\varepsilon_{\mathrm{M}}+D_{\mathrm{wo}}\right) \frac{\partial C}{\partial r}\right]-k_{\mathrm{r}}\left(C-C_{\mathrm{ws}}(T)\right)
$$

where for laminar flow, $\varepsilon_{\mathrm{H}}=\varepsilon_{\mathrm{M}}=0$. For turbulent flow, the following correlations for the momentum thermal and mass diffusivities are used ${ }^{15}$

$$
\begin{gathered}
\frac{\varepsilon_{\mathrm{M}}}{D_{\mathrm{wo}}} \equiv \frac{S c}{S c_{\mathrm{T}}} \frac{\varepsilon}{v} \\
\frac{\varepsilon_{\mathrm{H}}}{\alpha_{\mathrm{T}}} \equiv \frac{\operatorname{Pr}}{P r_{\mathrm{T}}} \frac{\varepsilon}{v} \\
P r_{\mathrm{T}}=S c_{\mathrm{T}} \approx 0.85
\end{gathered}
$$

The eddy momentum diffusivity $\varepsilon$ is obtained by the correlation of Van Driest ${ }^{16}$

$$
\frac{\varepsilon}{v}=\left(\kappa y^{+}\right)^{2}\left(1-e^{-y^{+} / A}\right)^{2}\left|\frac{d V_{z}^{+}}{d y^{+}}\right|
$$

The last term on the right-hand side of Eq. 4, $\left[k_{\mathrm{r}}(C-\right.$ $\left.C_{\mathrm{ws}}(T)\right)$ ], accounts for the rate of precipitation of wax in the oil. The rate of precipitation is assumed to be first order with respect to the difference between the supersaturated

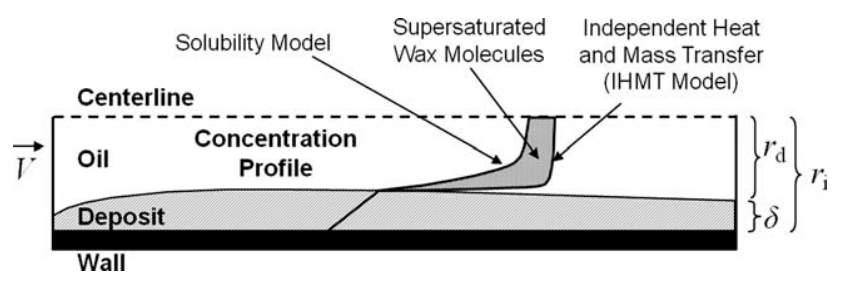

Figure 2. A comparison of the radial concentration profiles of wax between the IHMT model ${ }^{9}$ and the solubility model. ${ }^{12}$ 
concentration $C$ and the equilibrium concentration $C_{\mathrm{ws}}$, i.e., [ $\left.k_{\mathrm{r}}\left(C-C_{\mathrm{ws}}\right)\right]$, where $k_{\mathrm{r}}$ is the precipitation rate constant.

The boundary conditions for Eqs. 3 and 4 are shown as follows

$$
\begin{gathered}
\left\{\begin{array}{l}
T=T_{\text {inlet,oil }} \text { at } z=0 \\
\frac{\partial T}{\partial r}=0, \text { at } r=0 \\
h_{\mathrm{o}}\left(T_{\text {coolant }}-T_{\text {wall }}\right)=k_{\text {dep }} \frac{\partial T}{\partial r}, \text { at } r=r_{\mathrm{i}}
\end{array}\right. \\
\left\{\begin{array}{l}
C=C_{\text {inlet,oil }, \text { at } z=0} \\
\frac{\partial C}{\partial r}=0, \text { at } r=0 \\
C=C_{\text {ws }}(T), \text { at } r_{\mathrm{d}} \leq r \leq r_{\mathrm{i}}
\end{array}\right.
\end{gathered}
$$

The thermal boundary condition assumes a continuous heat flux at the wall with constant external heat-transfer coefficient, $h_{\mathrm{o}}$, which accounts for the thermal resistance of the insulation material and the coolant. The boundary condition for mass transfer assumes that the wax concentration follows liquid/solid equilibrium in the deposit. The above equations are solved by a backward implicit numerical scheme to obtain a stable solution. ${ }^{17}$

\section{The precipitation rate constant}

It can be seen in Eq. 4 that the precipitation rate constant, $k_{\mathrm{r}}$, determines the effect of precipitation of wax molecules in the bulk oil on wax deposition. It should be noted that if no precipitation of wax molecules occurs in the oil $\left(k_{\mathrm{r}}=0\right)$, the heat and mass transfer equations (Eqs. 3 and 4) are not related; thus, the model reduces to the IHMT model as the upper-bound prediction. As $k_{\mathrm{r}}$ increases and approaches infinity, the wax concentration becomes close to the thermodynamic equilibrium concentration, $C_{\mathrm{ws}}(T)$, which represents the lower-bound solubility model.

An approximation of $k_{\mathrm{r}}$ and its temperature dependence were found by the following analysis. The precipitation rate constant $k_{\mathrm{r}}$ (or equivalently the growth rate of wax nucleus in supersaturated solution) is zero if the temperature of oil is greater than the WAT. When the oil temperature is lower than the WAT, it is assumed that nucleation occurs over a short time and the size of the nuclei quickly reaches the critical nucleus size. ${ }^{18}$ In this case, the diffusion of the wax molecules to a wax nucleus is the rate-determining step for particle growth, and the growth rate of precipitated wax particles, $G\left(\mathrm{~kg} / \mathrm{m}^{3} / \mathrm{s}\right)$, can be estimated by Eq. $11^{19}$

$$
G=\underbrace{k_{\mathrm{d}} A_{\mathrm{n}} \rho_{\mathrm{n}}}_{k_{\mathrm{r}}}\left(C-C_{\mathrm{ws}}(T)\right)
$$

where $k_{\mathrm{d}}$ is the mass-transfer coefficient from the bulk to the individual nucleus surface, $A_{\mathrm{n}}$ is the surface area of a nucleus, and $\rho_{\mathrm{n}}$ is the number density of the nuclei. The mass-transfer coefficient $k_{\mathrm{d}}$ can be calculated from Eqs.12 and $13^{20}$

$$
\begin{gathered}
k_{\mathrm{d}}=\frac{S h_{\mathrm{n}} D_{\text {wo }}}{d_{\mathrm{n}}} \\
S h_{\mathrm{n}}=2+0.6 R e_{\mathrm{n}}^{0.5} S c_{\mathrm{n}}^{1 / 3} \cong 2
\end{gathered}
$$

where $d_{\mathrm{n}}$ is the diameter of the a nucleus and $S h_{\mathrm{n}}$ is the corresponding Sherwood number. Combining Eqs. 11-13 gives the expression for $k_{\mathrm{r}}$

$$
k_{\mathrm{r}}=\frac{\pi d_{\mathrm{n}} \rho_{\mathrm{n}}}{2} D_{\mathrm{wo}}(T)
$$

It is not possible to determine the exact values of $d_{\mathrm{n}}$ and $\rho_{\mathrm{n}}$ as they involve the solid-liquid thermodynamic equilibrium of a wax-oil system, which consists of thousands of components. However, one can find the dependence of $k_{\mathrm{r}}$ on temperature based on the dependence of diffusivity on temperature. To express $k_{\mathrm{r}}$ in terms of temperature, the correlation for diffusivity given by Hayduk and Minhas ${ }^{21}$ and the Arrhenius equation for the viscosity are used

$$
\begin{gathered}
D_{\text {wo }}=13.3 \times 10^{-12} \times \frac{T^{1.47} \mu^{\gamma}}{V_{\mathrm{A}}^{0.71}}, \gamma=\frac{10.2}{V_{\mathrm{A}}}-0.791^{*} \\
\mu=\mu_{\text {cloud }} \exp \left[\frac{E}{R}\left(\frac{1}{T}-\frac{1}{T_{\text {cloud }}}\right)\right]^{\dagger}
\end{gathered}
$$

Substituting Eqs. 15 and 16 into Eq. 14 and taking a ratio between $k_{\mathrm{r}}$ at any temperature and $k_{\mathrm{r}}$ at the cloud point, we have

$$
\frac{k_{\mathrm{r}}}{k_{\mathrm{r}, \text { cloud }}}=\left(\frac{T}{T_{\text {cloud }}}\right)^{1.47} \exp \left[\frac{\gamma E}{R}\left(\frac{1}{T}-\frac{1}{T_{\text {cloud }}}\right)\right]^{\dagger}
$$

where the precipitation rate parameter at the cloud-point temperature, $k_{\mathrm{r} \text {,cloud }}$, is the only adjustable parameter in this model. For the two crude oils in this study (the South Pelto oil and the Garden Bank condensate), the $k_{\mathrm{r} \text {,cloud }}$ is virtually the same. Simulations on other oils also suggest that $k_{\mathrm{r}, \mathrm{cloud}}$ falls in the range of $1-10 \mathrm{~s}^{-1}$.

It should be noted that although $k_{\mathrm{r}, \mathrm{cloud}}$ is adjustable, it is bounded in a range estimated from first principles. Based on the values of $k_{\mathrm{r} \text {,cloud }}$ in this study, the particle number density, $\rho_{\mathrm{n}}$, was back calculated by Eq. 14 and was found to fall between full precipitation based on equilibrium assumption (maximum number density with critical nucleus size) as the upper bound and microscopic observation in the deposit (minimum number density with fully grown wax crystals) as the lower bound. The details of this calculation are given by Lee. $^{22}$

\section{Deposition mechanism}

Because molecular diffusion is the deposition mechanism, the diffusive mass flux into the deposit contributes to the increase of the wax fraction in the deposit ${ }^{10}$

$$
\pi \rho_{\text {deposit }}\left(r_{\mathrm{i}}^{2}-r_{\mathrm{d}}^{2}\right) \frac{d \bar{F}_{\mathrm{w}}}{d t}=2 \pi r_{i}\left(-\left.D_{\text {eff }} \frac{d C}{d r}\right|_{\text {interface,diffusive }}\right)
$$

The difference between the convective mass flux to the fluid-deposit interface and the diffusive mass flux into the deposit represents the growth of the deposit thickness ${ }^{10}$

\footnotetext{
*In Eq. 15, the unit of viscosity is $\mathrm{mPa}$ s.

${ }^{\dagger}$ In Eqs. 16 and 17 , the unit for temperature is $\mathrm{K}$ instead of ${ }^{\circ} \mathrm{C}$ as is in the nomenclature, the figures, and tables in this study.
} 
Table 2. Summary of the Oil Properties and Operating Conditions in the Lab-Scale and the Pilot-Scale Experiments

\begin{tabular}{|c|c|c|c|}
\hline & Singh et al. ${ }^{9}$ & Hernandez $^{24}$ & Lund $^{25}$ \\
\hline Cloud point $\left({ }^{\circ} \mathrm{C}\right)$ & 13.9 & 34.4 & 49.0 \\
\hline Wax content (wt \%) & 0.67 & 3.55 & $6.6 \%$ \\
\hline Length of the pipe (m) & 2.44 & 50 & 50 \\
\hline Oil inlet temperature $\left({ }^{\circ} \mathrm{C}\right)$ & 22.2 & 29.44 & 40.6 \\
\hline Coolant inlet temperature $\left({ }^{\circ} \mathrm{C}\right)$ & 7.2 & 12.78 & 15.6 \\
\hline Oil flow rate $\left(\mathrm{m}^{3} / \mathrm{s}\right)$ & $6.3 \times 10^{-5}$ & $3.31 \times 10^{-3}$ & $2.76 \times 10^{-3}$ \\
\hline Reynolds number & 799 & 24,524 & 11,270 \\
\hline Wall shear stress $(\mathrm{Pa})$ & 7.73 & 14 & 20 \\
\hline Estimated wall heat flux $\left(\mathrm{J} / \mathrm{m}^{2} / \mathrm{s}\right)$ & 1094 & 5512 & 5700 \\
\hline Solubility measurement & DSC & Thermodynamic module & Thermodynamic module and DSC \\
\hline
\end{tabular}

$$
\begin{aligned}
2 \pi r_{i} \rho_{\text {deposit }} \bar{F}_{\mathrm{w}} \frac{d \delta}{d t}=2 \pi r_{\mathrm{d}}\left(-\left.D_{\text {wo }} \frac{d C}{d r}\right|_{\text {interface,convective }}\right) \\
-2 \pi r_{\mathrm{d}}\left(-\left.D_{\text {eff }} \frac{d C}{d r}\right|_{\text {interface,diffusive }}\right)
\end{aligned}
$$

where $D_{\text {wo }}$ is the diffusivity of wax in oil calculated by the correlation of Hayduk and Minhas, ${ }^{21}$ and $D_{\text {eff }}$ is the effective diffusivity of wax in the deposit calculated by the correlation of Cussler et al. ${ }^{23}$

\section{Results and Discussion}

In this section, the accuracy of the MWP model will be verified first in a lab-scale laminar flow experiment ${ }^{9}$ and then by two pilot-scale turbulent flow-loop experiments. ${ }^{24,25}$ Finally, the model is applied to the prediction of field-scale pipelines. The properties of the oils and the operating conditions of these three experiments are reported in the studies referenced above and are summarized in Table 2, whereas the viscosity and the solubility curves of these three oils are shown in Figures 3 and 4 , respectively. These operating conditions and material properties are used as the inputs to the model simulation.

\section{Lab-scale laminar flow-loop experiments}

A lab-scale flow-loop experimental result is first compared to the computational wax deposition model that

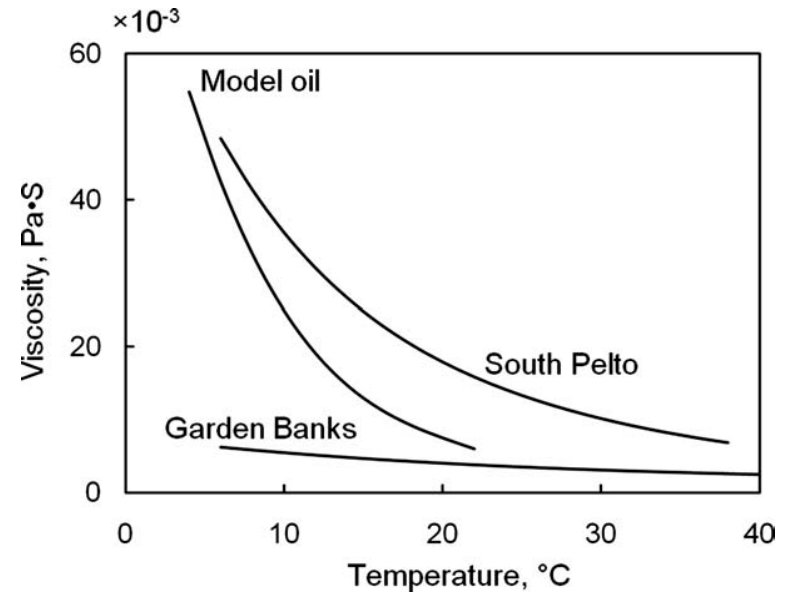

Figure 3. Viscosity as a function of temperature of the South Pelto Crude oil, ${ }^{25}$ the Garden Bank condensates, ${ }^{24}$ and the model oil. ${ }^{9}$ includes precipitation kinetics. ${ }^{9}$ A mixture of a 3:1 volume ratio of mineral oil (Blandol) and kerosene is blended with 0.67 wt $\%$ of food-grade wax with carbon numbers ranging from $\mathrm{C}_{23}$ to $\mathrm{C}_{38}$.

Figure 5 compares the deposit thickness measured in the experiment with that predicted by the MWP. Table 3 shows the comparison of the wax fractions at the end of the experiment. It is seen that the model accurately predicts both the deposit thickness and the wax fraction in the deposit. The precipitation rate constant at the cloud-point temperature, $k_{\mathrm{r} \text {,cloud, }}$ in this case was $0 \mathrm{~s}^{-1}$, indicating that precipitation rate is negligible for laminar flow conditions. This agreement between the experiment and the model prediction explains the success of the model of Singh et al. ${ }^{9}$ using IHMT correlations.

\section{Pilot-scale turbulent flow-loop experiments}

To provide the transition from lab-scale experiments to field-scale pipeline systems, the MWP is now applied to a two pilot-scale turbulent flow-loop experiments, one carried out by Hernandez ${ }^{24}$ (Test Wax2001/029) and the other by Lund (Test 14R). ${ }^{25}$ Unlike the model wax oil used in labscale tests discussed in the previous sections, two crude oils (the Garden Bank condensate and the South Pelto oil) are used in this case.

The model was first applied to the deposition experiment of the Garden Bank condensate. Similar to field-scale pipelines, the bulk temperature of oil in the large-scale flow-loop

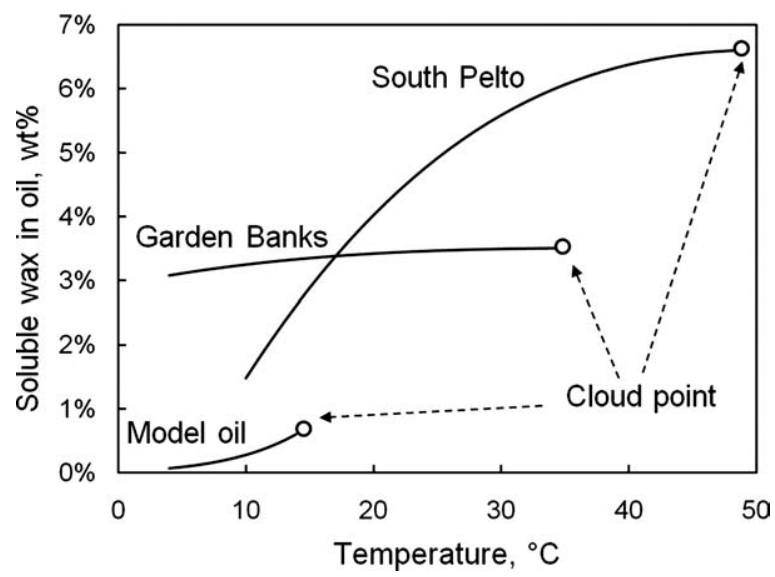

Figure 4. Solubility as a function of temperature of the South Pelto Crude oil, ${ }^{25}$ the Garden Bank condensates, ${ }^{24}$ and the model oil. ${ }^{9}$ 


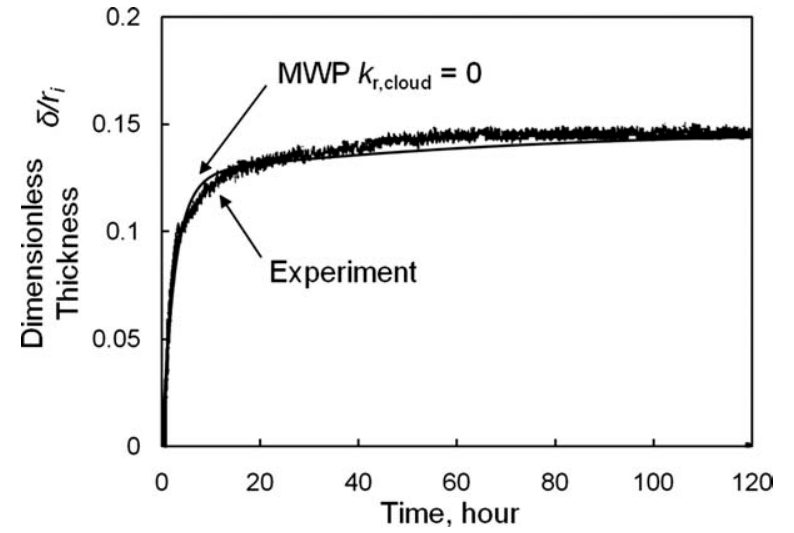

Figure 5. Comparison between the experimental and the predicted deposit thickness for the labscale laminar flow loop.

changes with respect to the axial location. Figure 6 shows the comparison between the bulk temperature of oil measured as a function of axial distance at $t=0$ before wax deposition begins and that calculated by the MWP. The excellent match indicates a satisfactory evaluation of the heat transfer of the experiment, which is vital for predicting the growth of the deposit and the wax fraction in the wax deposit. Figure 7 compares the deposit thickness measured during the experiment with that predicted by the MWP. Table 4 shows the comparison of the wax fractions measured at the end of the experiment with that predicted by the MWP.

It is seen that the upper-bound IHMT approach $\left(k_{\mathrm{r}, \text { cloud }}=\right.$ $0)$ overpredicts the deposit thickness because it overestimates the number of wax molecules transported to the wall for deposition. By choosing a large value of $k_{\mathrm{r}, \text { cloud }}$ (e.g., $10^{3}$ $\mathrm{s}^{-1}$ ), the model approximates the solubility model, which is shown as the lower bound in Figure 7. In this case, the supersaturated wax molecules are assumed to precipitate nearly instantaneously so that few of them are left for deposition. Excellent agreement can be seen between the model and the experiment for the deposit thickness and for the wax fraction when $k_{\mathrm{r} \text {,cloud }}=1.4 \mathrm{~s}^{-1}$. This value will be used for further field-scale predictions.

In addition to the Garden Bank condensate, the MWP is also applied to the prediction of the experiment with the South Pelto crude oil. Figure 8 compares the deposit thickness obtained by the MWP, whereas Table 4 shows comparison of the wax fractions at the end of the experiment.

Similar conclusions to the experiment with Garden Bank condensate are found, namely that the experiment can be bounded by the IHMT approach as the upper bound and the solubility method as the lower bound, while the model gives the best prediction of both the deposit thickness and the wax

Table 3. Comparison between the Experimental and Predicted Wax Fraction for the Lab-Scale Laminar Flow-Loop Experiment with Model Oil ${ }^{9}$

\begin{tabular}{ccc}
\hline & Experiment & MWP $\left(k_{\mathrm{r}, \text { cloud }}=0\right)$ \\
\hline $\begin{array}{c}\text { Wax fraction in } \\
\text { the deposit }\end{array}$ & $0.153 \pm 0.025$ & 0.157 \\
\hline
\end{tabular}

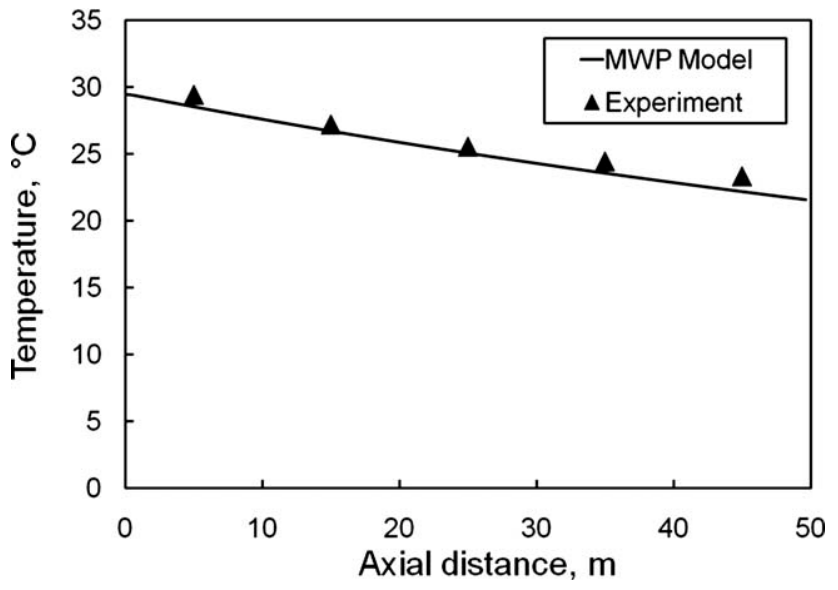

Figure 6. Comparison between bulk temperatures measured in the pipe and that predicted by the MWP for the pilot-scale deposition experiments with the Garden Bank condensate.

fraction for a bulk precipitation rate constant, $k_{\mathrm{r} \text {,cloud }}$ of $1.4 \mathrm{~s}^{-1}$. In addition, it can be seen that the precipitation rate constant is essentially the same for the South Pelto oil and the Garden Bank condensate, indicating that the precipitation kinetics of oil under turbulent flow conditions are quite similar.

\section{Field-scale predictions}

One of the major differences between small-scale (labscale and pilot-scale) flow-loop system and field-scale pipelines is rate of the radial heat transfer. In the previous flowloop experiments, the radial thermal resistance was designed to be much smaller than for field conditions to minimize the experimental time (i.e., several days at most). However, in field conditions, the existence of insulating materials helps increase the thermal resistance and decrease the radial heat loss of the oil. Now that the MWP has been verified for both lab-scale and pilot-scale flow-loop experiments, and the model can be used to predict wax deposition in field-scale

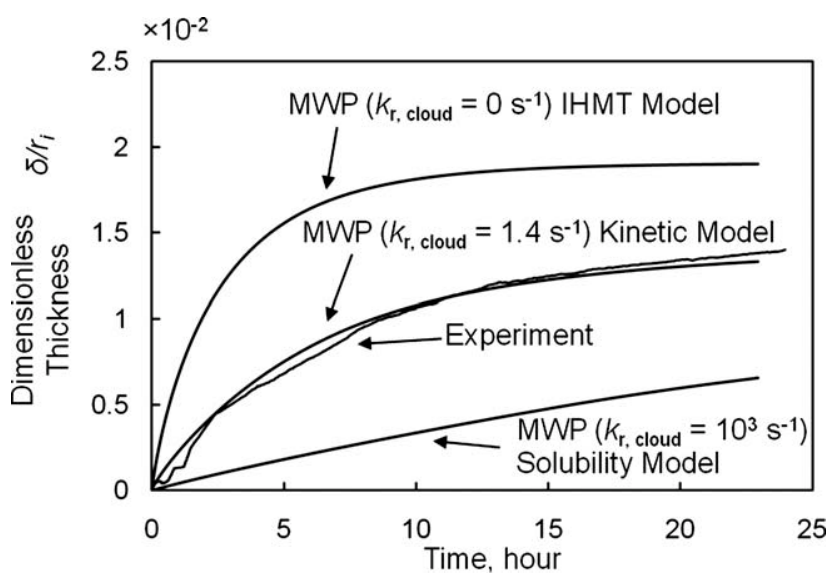

Figure 7. Comparison between experimental deposit thickness and that predicted by MWP for the pilot-scale experiment with the Garden Bank condensate. 
Table 4. Comparison between Experimental and the Predicted Wax Fraction for the Pilot-Scale Turbulent Flow-Loop Experiment with the Garden Bank Condensate ${ }^{24}$ and the South Pelto Crude Oil ${ }^{25}$

\begin{tabular}{lcccc}
\hline & Experimental Wax Fraction & MWP $\left(k_{\mathrm{r}, \text { cloud }}=0\right)$ & MWP $\left(k_{\mathrm{r}, \text { cloud }}=1.4 \mathrm{~s}^{-1}\right)$ & MWP $\left(k_{\mathrm{r}, \text { cloud }}=10^{3} \mathrm{~s}^{-1}\right)$ \\
\hline Garden Bank condensate & $0.35 \pm 0.05$ & 0.18 & 0.31 & 0.52 \\
South Pelto crude oil & $0.42 \pm 0.05$ & 0.30 & 0.45 & 0.56 \\
\hline
\end{tabular}

pipelines. Table 5 summarizes the operating parameters used for field-scale predictions. Additionally, three oils will be used: the Garden Bank condensate, ${ }^{24}$ the South Pelto oil, ${ }^{25}$ and the model oil. ${ }^{12}$

\section{Predictions using the Garden Bank condensate as the base case}

Figure 9 shows the axial profile of the predicted deposit thickness (the left axis) after 180 days using the Garden Bank condensate as the base case. It is seen that the deposit profile can be divided into three sections: (1) no deposition, (2) significant deposition, and (3) insignificant deposition. No deposit occurs in the first section $(0-33 \mathrm{~km})$ where the inner wall temperature is higher than the cloud-point temperature (the right axis). As the fluid enters the second section $(33-170 \mathrm{~km})$, the inner wall temperature has now dropped below the WAT where wax molecules start to deposit on the wall, resulting in significant wax build up in this section. When the fluid enters the third section $(>170 \mathrm{~km})$, the bulk temperature of the oil has decreased significantly and is close to the ocean floor temperature, causing a decrease of the radial thermal gradient in the oil. This decrease in the radial thermal gradient reduces the driving force for wax deposition, i.e. $\left(C_{\text {bulk }}-C_{\text {interface }}\right)$, and leads to insignificant deposition in this section.

Figure 10 shows the axial profile of the predicted wax fraction in the deposit for the Garden Bank condensate. Similar to the thickness profile, the wax fraction has a maximum in this section of the pipe where the radial driving force for mass transfer is the greatest. The strength of the deposit strongly depends on its wax fraction. Therefore, both the deposit thickness and wax fraction profile are important variables in planning remediation techniques for wax deposition. ${ }^{9}$

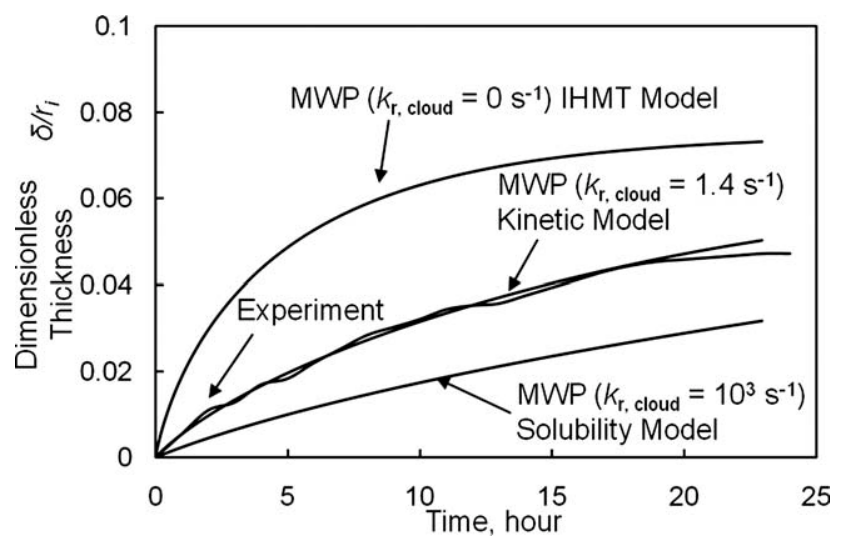

Figure 8. Comparison between experimental deposit thickness and that predicted by MWP for the pilot-scale experiment with the South Pelto crude oil.

\section{Comparisons of different precipitation rate constants}

The previous field-scale prediction applied the kinetic model using a precipitation rate constant at the cloud-point temperature, $k_{\mathrm{r}, \mathrm{cloud}}$, of $1.4 \mathrm{~s}^{-1}$. This value is obtained from the pilot-scale experiment. To compare the field-scale prediction using the kinetic method with the IHMT model and the solubility model, simulations were carried out under the same operating conditions for the Garden Bank condensate using different precipitation rate constants. Figure 11 shows the comparison of the simulations for the three models.

The predicted deposit profiles using three different precipitation rate constants represent trends similar to the pilotscale predictions (Figure 7). A drastic difference can be observed between IHMT method (the upper bound with $k_{\mathrm{r}, \text { cloud }}=0$ ) and the other two methods. This difference is due to the assumption in the IHMT model that no precipitation of wax occurs in the bulk even when the temperature at the outlet has decreased nearly to the ocean-floor temperature (Figure 9, right axis). This unrealistic assumption causes a significant overestimation of the driving force for wax deposition and drastically overpredicts the growth of the deposit. On the other hand, when nearly instantaneous precipitation is assumed, the solubility model (the lower bound with $k_{\mathrm{r} \text {,cloud }}=10^{3}$ ) underpredicts the deposition thickness, causing a potential hazard for field remediation operations.

\section{The effect of the solubility curve in field-scale predictions}

The solubility of waxes plays a very important role in wax deposition in field-scale pipelines where the temperature of oil changes significantly along the pipe. ${ }^{26}$ In this research, the effect of solubility on the wax deposition in field-scale pipelines is investigated by conducting wax deposition simulation for three oils: the Garden Bank condensates, ${ }^{24}$ the South Pelto crude oil, ${ }^{25}$ and the model oil used by Singh et al. ${ }^{9}$ Because our previous modeling of the pilot-scale deposition experiments found that the precipitation rate constant at the cloud point, $k_{\mathrm{r} \text {,cloud }}$, was similar for the oils in turbulent flow conditions, the value of $1.4 \mathrm{~s}^{-1}$ will be used for field-scale predictions. The properties of these oils are shown in Table 1. The solubility curves of three oils are shown in Figure 4.

Table 5. Conditions for the Base Case of a Field-Scale Pipeline System

\begin{tabular}{lc}
\hline \multicolumn{1}{c}{ Operating Parameters } & Value \\
\hline Inner diameter of the pipe $(\mathrm{cm})$ & $6.35(5 \mathrm{inch})$ \\
Length of the pipe $(\mathrm{km})$ & 70 \\
Flow rate of oil $(\mathrm{bpd})$ & 30,000 \\
Flow rate of oil $\left(\mathrm{m}^{3} / \mathrm{s}\right)$ & $5.52 \times 10^{-2}$ \\
Inlet temperature of oil $\left({ }^{\circ} \mathrm{C}\right)$ & 70 \\
Ocean floor temperature $\left({ }^{\circ} \mathrm{C}\right)$ & 4 \\
External heat transfer coefficient $\left(\mathrm{W} / \mathrm{m}^{2} / \mathrm{K}\right)$ & 5 \\
\hline
\end{tabular}




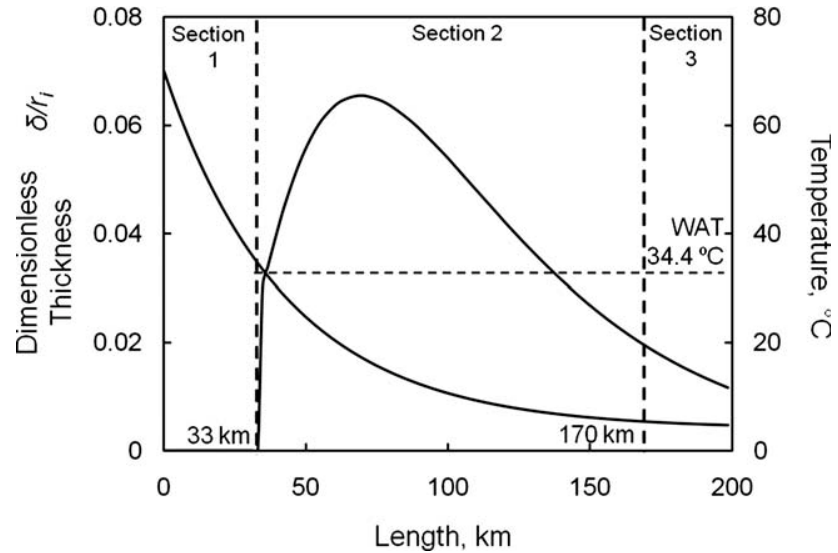

Figure 9. Prediction of the oil-deposit interface temperature along the pipe as the base case with the Garden Bank condensate after 180 days.

Two major elements in the solubility curve significantly affect wax deposition: the cloud-point temperature and the gradient of the solubility curve. The cloud point of the oil determines the onset location of deposition in a subsea pipeline. The gradient of the solubility curve is a strong indicator of how much wax will precipitate on the wall when the temperature decreases along the pipe and thus greatly affects the amount of deposition. Figure 12 shows the axial profiles for the predicted deposit thickness for the three different oils after 180 days of continuous operation.

It is seen that the deposition of the South Pelto oil occurs shortly after the inlet with the highest maximum deposit thickness because this oil has the highest cloud point and its solubility gradient is significantly greater than that of the other two oils. The model oil has the lowest cloud point and its onset of deposition is furthest from the inlet. In addition, one notes the difference in the deposition characteristics between a model oil system and a real field oil system: in the case of the model oil system significant deposition occurs over a relatively short range (90-140 km) of the pipe, whereas significant deposition can be found in a much longer portion of the pipe for the real oils (17-200 km for

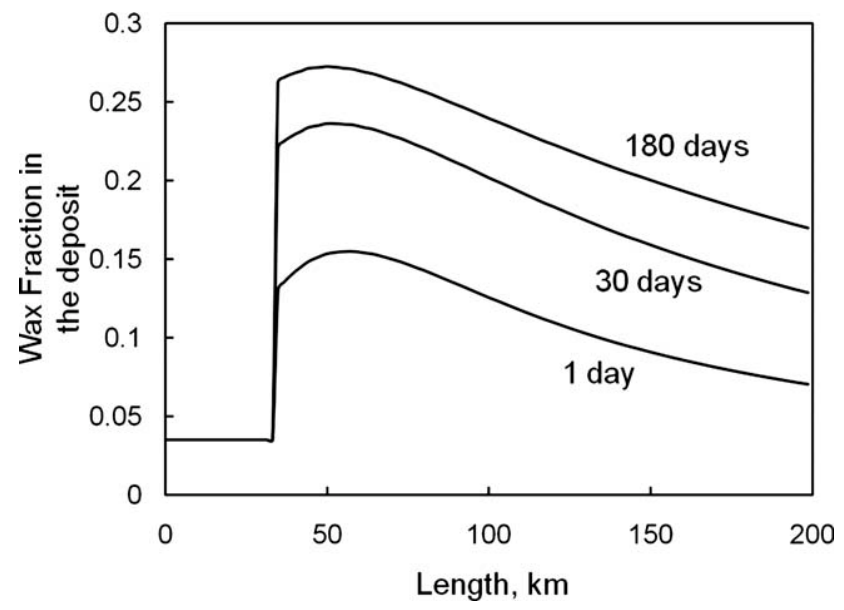

Figure 10. Prediction of the wax fraction in the deposit along the pipe for the base case $\left(k_{\mathrm{r}}=1.4 \mathrm{~s}^{-1}\right)$.

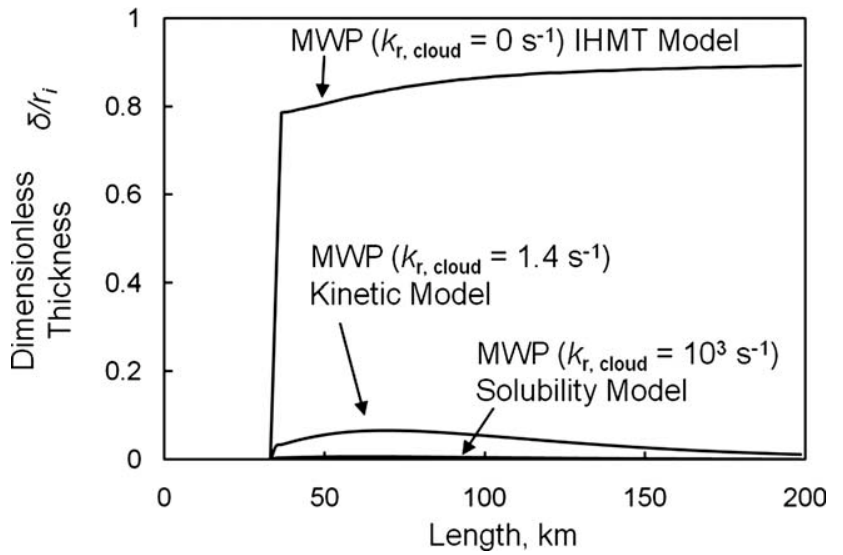

Figure 11. Comparison of field-scale predictions for different precipitation rate constants after 180 days.

South Pelto and 33-200 km for Garden Bank). This difference is closely related to the difference in their composition of $n$-paraffins, which is shown in Figure 13.

The wax in the model oil system has a narrower carbon number distribution of wax compared with the other real field oils. Therefore, as the temperature decreases along the pipe flow, precipitation in the model oil will primary occur over a certain section of the pipe within a small temperature range. Contrarily, the two other real oils have broader carbon number distributions and the wax in these two oils can precipitate over a wider range of temperature. Therefore, deposition is seen in a large portion of the pipe.

\section{Conclusions}

In this research, a wax deposition prediction model (the MWP) was developed with fundamental analysis of transport phenomena under pipe-flow conditions. Instead of using empirical correlations for the heat and mass transfer, the model solves the transport equations numerically to study the effect of precipitation of wax molecules in the bulk on deposition. This bulk precipitation is found to reduce wax deposition by

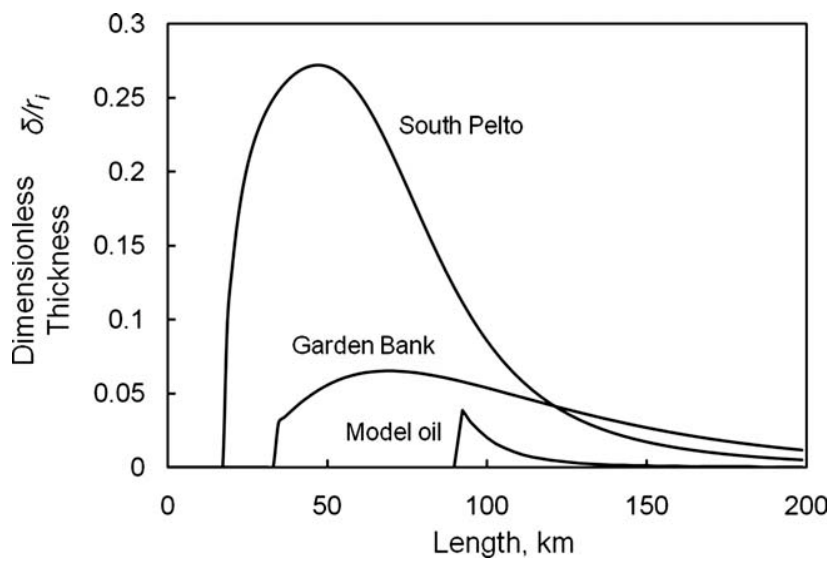

Figure 12. Axial thickness profiles for various oils.

The input parameters used for these simulations are summarized in Table 5. 


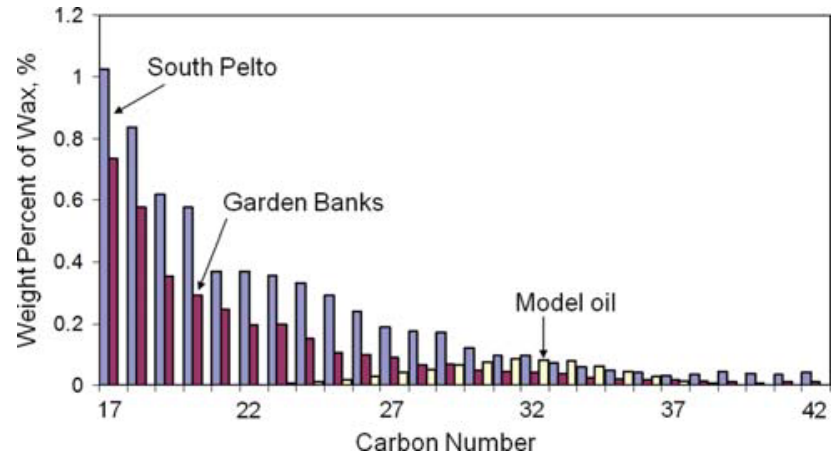

Figure 13. Comparison of the carbon number distribution of $n$-paraffin among the South Pelto $\mathrm{oil}^{25}$, the Garden Bank ${ }^{24}$ condensate, and the model oil. ${ }^{9}$

[Color figure can be viewed in the online issue, which is available at wileyonlinelibrary.com.]

decreasing the amount of dissolved wax molecules that can potentially deposit on the wall. By changing the bulk precipitation rate constant, $k_{\mathrm{r}}$, it is found that the deposit profile falls between the bounds given by two previous models: the IHMT model as the upper bound (no bulk precipitation) and the solubility model as the lower bound (instantaneous bulk precipitation). More importantly, the MWP accurately predicted the growth of wax deposit and the wax fraction in the deposit with $k_{\mathrm{r}, \text { cloud }}$ being the only adjustable parameter, which was found to be similar for different oils flowing under similar conditions.

After verifying the model with various flow-loop experiments, the model was applied to wax deposition predictions for field-scale pipelines. It is seen that the difference between the IHMT model and the solubility model is amplified, indicating that the precipitation in the bulk oil becomes significant in field pipelines where the oil temperature decreases significantly to reduce the driving force for wax deposition. Furthermore, wax deposition occurs in a much shorter section of the pipe for the model oil than for the two real oils. This difference is due to the intrinsic difference in the carbon number distribution of the paraffins in the oil and its effect on the cloud point and the solubility curve.

\section{Acknowledgments}

The authors acknowledge the financial support from the following members of the University of Michigan Industrial Affiliates Program: Chevron Corporation, ConocoPhillips Company, Multiphase Solutions Inc, Nalco Company, Shell Global Solutions, Schlumberger Limited, Statoil ASA, and Total S.A.

\section{Notation}

\section{Hydrodynamics}

$A=$ constant for the correlation of eddy viscosity in Eq. $8, A=26$

$A_{\mathrm{p}}=$ surface area of the particle $\left(\mathrm{m}^{2}\right)$

$E=$ activation energy for the viscosity equation $(\mathrm{J} / \mathrm{mol})$

$L=$ length of the pipe $(\mathrm{m})$

$Q=$ flow rate $\left(\mathrm{m}^{3} / \mathrm{s}\right)$

$R=$ ideal gas constant $(8.314 \mathrm{~J} / \mathrm{K} / \mathrm{mol})$

$R e=$ Reynolds number

$V=$ velocity $(\mathrm{m} / \mathrm{s})$

$V^{+}=$dimensionless velocity from the wall for Eq. 8

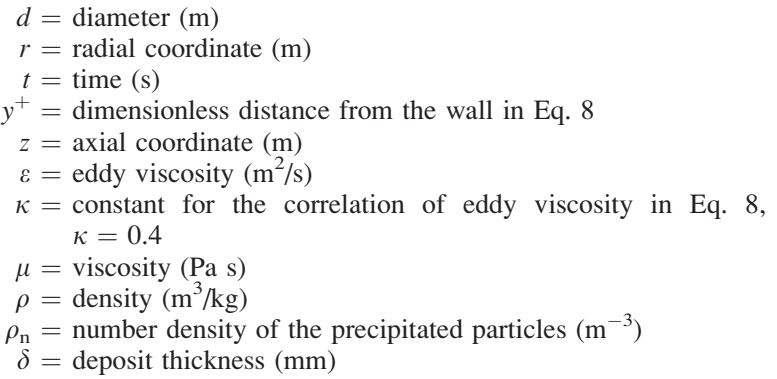

\section{Heat/Mass Transfer}

$C=$ concentration of wax molecules $\left(\mathrm{kg} / \mathrm{m}^{3}\right)$

$C_{\mathrm{p}}=$ specific heat $(\mathrm{J} / \mathrm{K} / \mathrm{kg})$

$D_{\text {wo }}=$ diffusivity of wax in oil $\left(\mathrm{m}^{2} / \mathrm{s}\right)$

$D_{\text {eff }}=$ effective diffusivity of wax in the deposit

$\bar{F}_{\text {w }}=$ wax fraction in the deposit

$G=$ growth rate of precipitated wax particles $\left(\mathrm{kg} / \mathrm{m}^{3} / \mathrm{s}\right)$

$\operatorname{Pr}=$ Prandtl number

$S c=$ Schmidt number

$\mathrm{Nu}=$ Nusselt number

$S h=$ Sherwood number

$T=$ temperature $\left({ }^{\circ} \mathrm{C}\right)$

$V_{\mathrm{A}}=$ molecular volume of the paraffin in Eq. $15\left(\mathrm{~cm}^{3} / \mathrm{mol}\right)$

$h_{\mathrm{o}}=$ external heat-transfer coefficient $\left(\mathrm{W} /\left(\mathrm{m}^{2} \mathrm{~K}\right)\right)$

$k_{\mathrm{r}}=$ rate constant for precipitation of wax $\left(\mathrm{s}^{-1}\right)$

$k_{\text {dep }}=$ thermal conductivity of the deposit $(\mathrm{W} / \mathrm{m} / \mathrm{K})$

$k_{\mathrm{d}}=$ mass-transfer coefficient from the bulk to the individual nucleus surface $(\mathrm{m} / \mathrm{s})$

$\alpha_{\mathrm{T}}=$ thermal diffusivity of the oil $\left(\mathrm{m}^{2} / \mathrm{s}\right)$

$\varepsilon_{\mathrm{H}}=$ eddy thermal diffusivity $\left(\mathrm{m}^{2} / \mathrm{s}\right)$

$\varepsilon_{\mathrm{M}}=$ eddy mass diffusivity $\left(\mathrm{m}^{2} / \mathrm{s}\right)$

\section{Subscripts}

$\mathrm{d}=$ from centerline to the deposit (for radial coordinates)

$\mathrm{i}=$ from centerline to the inner wall (for radial coordinates)

$\mathrm{n}=$ nucleus

$\mathrm{t}=$ turbulent flow

$\mathrm{z}=$ axial direction

$R e=$ Reynolds number

bulk $=$ properties of the bulk oil

oil $=$ properties of the oil

coolant $=$ properties of the coolant

cloud $=$ properties at the cloud-point temperature

inlet $=$ properties at the inlet

interface $=$ properties at the oil-deposit interface

wall $=$ properties at the inner wall

$\mathrm{ws}=$ solubility of wax

\section{Literature Cited}

1. Gluyas JG, Underhill JR. United Kingdom oil and gas fields. Geol Soc. 2003;20:327-333.

2. Lee HS, Singh P, Thomason WH, Fogler HS. Waxy oil gel breaking mechanisms: adhesive versus cohesive failure. Energy Fuels. 2007; 22:480-487.

3. Fung G, Backhaus WP, McDaniel S, Erdogmus M. To pig or not to pig: the marlin experience with stuck pig. In: Proceedings of Offshore Technology Conference, Houston, USA, 2006.

4. Singh P, Fogler HS. Fused chemical reactions: the use of dispersion to delay reaction time in tubular reactors. Ind Eng Chem Res. 1998; 37:2203-2207.

5. Nguyen AD, Fogler HS, Sumaeth C. Fused chemical reactions. II. Encapsulation: application to remediation of paraffin plugged pipelines. Ind Eng Chem Res. 2001;40:5058-5065.

6. Bern PA, Withers VR, Cairns JR. Wax deposition in crude oil pipelines. In: Proceedings of European Offshore Petroleum Conference and Exhibition, London, UK, 1980.

7. Burger ED, Perkins TK, Striegler JH. Studies of wax deposition in the trans Alaska pipeline. J Petrol Technol. 1981;33:1075-1086. 
8. Majeed A, Bringedal B, Overa S. Model calculates wax deposition for N. Sea oils. Oil Gas J. 1990;88:63-69.

9. Singh P, Venkatesan R, Fogler HS, Nagarajan NR. Formation and aging of incipient thin film wax-oil gels. AIChE J. 2000;46:1059-1074.

10. Singh P, Venkatesan R, Fogler HS, Nagarajan NR. Morphological evolution of thick wax deposits during aging. AIChE J. 2001;47:6-18.

11. Venkatesan R, Fogler HS. Comments on analogies for correlated heat and mass transfer in turbulent flow. AIChE J. 2004;50:1623-1626.

12. Venkatesan R. The deposition and rheology of organic gels. PhD Thesis, Dept. of Chemical Engineering, University of Michigan, 2004.

13. Seider EN, Tate CE. Heat transfer and pressure drop of liquids in tubes. Ind Eng Chem. 1936;28:1429-1435.

14. Dittus FW, Boelter LMK. Heat transfer in automobile radiators of the tubular type. Publ Eng. 1930;2,443-461.

15. Geankoplis CJ. Transport Process and Separation Process Principles, 4th ed. Englewood Cliffs, NJ: Prentice Hall, 2003.

16. Van Driest ER. On turbulent flow near a wall. J Aero Sci. 1956;23. 1007-1011.

17. Tanehill JC, Anderson DA, Pletcher RH. Computational Fluid Mechanics and Heat Transfer. Philadelphia, PA: Taylor and Francis, 1997.

18. Fogler HS. Elements of Chemical Reaction Engineering, 4th ed. Upper Saddle River, NJ: Prentice Hall, 2006.
19. Marchisio DL, Barresi AA, Garbero M. Nucleation, growth and agglomeration in barium sulfate turbulent precipitation. AIChE J. 2002;48:2039-2050.

20. Armenante PM, Kirwan DJ. Mass transfer to microparticles in agitated systems. Chem Eng Sci. 1989;44:2781-2796.

21. Hayduk W, Minhas BS. Correlations for prediction of molecular diffusivities in liquids. Can J Chem Eng. 1982;60:295-299.

22. Lee HS. Computational and rheological study of wax deposition and gelation in subsea pipelines. PhD thesis, University of Michigan, 2007.

23. Cussler EL, Hughes SE, Ward WJ, Aris R. Barrier membranes. J Membr Sci. 1988;38:161-174.

24. Hernandez OC. Investigation of single-phase paraffin deposition characteristics. M.S. Thesis, University of Tulsa, 2002.

25. Lund $H$. Investigation of paraffin deposition during single-phase liquid flow in pipelines. M.S. Thesis, University of Tulsa, 1998.

26. Han S, Huang Z, Senra M, Hoffmann R, Fogler HS. Method to determine the wax solubility curve from centrifugation and high temperature gas chromatography measurements. Energy Fuels. 2010; 24:1753-1761.

Manuscript received May 28, 2010, revision received Oct. 27, 2010, and final revision received Dec. 7, 2010. 